\title{
What Factors Influence the Success of Medial Gastrocnemius Flaps in the Treatment of Infected TKAs?
}

\author{
Matthew W. Tetreault MD, Craig J. Della Valle MD, Daniel D. Bohl MD, MPH, \\ Sameer J. Lodha MD, Debdut Biswas MD, Robert W. Wysocki MD
}

Received: 9 August 2015/Accepted: 2 November 2015/Published online: 16 November 2015

(C) The Association of Bone and Joint Surgeons ( 2015

\begin{abstract}
Background Soft tissue defects after TKA are a potentially devastating complication. Medial gastrocnemius flaps occasionally are used to provide soft tissue coverage, most commonly with a periprosthetic joint infection.

Questions/Purposes We asked: (1) What were the rates of persistent or recurrent infection, implant survivorship, flaprelated complications, and reoperation for patients who underwent medial gastrocnemius flap reconstruction for soft tissue coverage after TKA? (2) What were the Knee Society clinical and functional scores for patients who
\end{abstract}

One author (CJDV) has received research support funding from Biomet Inc (Warsaw, IN, USA), Smith \& Nephew Inc (Memphis, TN, USA), Stryker (Mahwah, NJ, USA) and DePuy, (Warsaw, IN, USA). The institution of one or more of the authors (CJDV) has received, during the study period, funding from Zimmer Inc (Warsaw, IN, USA).

One author (CJDV), or a member of his or her immediate family, has or may receive payments or benefits, during the study period, an amount of USD 10,000-USD 100,000 from Biomet Inc (Warsaw, IN, USA), an amount of USD 10,000-USD 100,000 from DePuy Synthes (Warsaw, IN, USA), an amount of less than USD 10,000 from Smith \& Nephew Inc (Memphis, TN, USA), and an amount of less than USD 10,000 from CD Diagnostics (Wynnewood, PA, USA).

All ICMJE Conflict of Interest Forms for authors and Clinical Orthopaedics and Related Research ${ }^{\mathbb{R}}$ editors and board members are on file with the publication and can be viewed on request.

Each author certifies that his or her institution approved the human protocol for this investigation, that all investigations were conducted in conformity with ethical principles of research, and that informed consent for participation in the study was obtained.

M. W. Tetreault, C. J. Della Valle (凹), D. D. Bohl,

S. J. Lodha, D. Biswas, R. W. Wysocki

Department of Orthopaedic Surgery, Rush University Medical

Center, 1611 West Harrison Street, Suite 300, Chicago,

IL 60612, USA

e-mail: craigdv@yahoo.com underwent medial gastrocnemius flap reconstruction for soft tissue defects after TKA? (3) What were the risk factors for failure of medial gastrocnemius flap reconstruction after TKA, with failure defined as recurrent or new periprosthetic joint infection or inability to reimplant the TKA prosthesis?

Methods Between 2003 and 2011, four surgeons at one institution performed 31 medial gastrocnemius flaps for soft tissue coverage over an infected TKA. Of those, 27 $(87 \%)$ were available for followup at a minimum of 2 years (mean, 4 years; range, 2-6 years), although patients experiencing complications or treatment failures before two years were included. The study group consisted of 15 men and 12 women with a mean age of 61 years at the time of surgery (range, 36-86 years). The general indication for using a gastrocnemius flap in this setting was full-thickness soft tissue deficiency over the anterior knee during the course of treatment for concomitant deep infection. Six flaps were performed at prosthetic explantation and antibiotic spacer placement, eight at a spacer exchange, eight at second-stage TKA prosthesis reimplantation, and five at débridement with polyethylene exchange. The decision regarding when during staged treatment to place the flap was based solely on when the soft tissues were deemed insufficient, and not based on a belief that placement at one stage versus another was advantageous. Failure was defined as inability to undergo reimplantation of a TKA prosthesis or recurrence of periprosthetic joint infection. Patient and procedural characteristics were tested for association with failure. Survivorship was calculated by Cox proportional hazards modeling. Outcomes scores were drawn from a longitudinal institutional registry.

Results Fourteen of $27(52 \%)$ patients had a persistent or recurrent infection; survivorship of the TKA prosthesis at 4 years was $48 \%$ (95\% CI, 31\%-66\%). Although there were 
no flap-related complications, 12 patients had a total of 19 reoperations during the study period. Overall, the mean $( \pm$ SD) Knee Society knee $(38 \pm 18$ vs $65 \pm 20 ; p<0.001)$ and function $(20 \pm 22$ vs $37 \pm 25 ; p=0.002)$ scores were improved at most recent followup. No factors were identified as associated with failure when a Bonferroni correction was applied.

Conclusions Gastrocnemius flaps were used to address difficult soft tissue defects in this series, in the presence of deep infections; the high proportion of patients experiencing persistent or recurrent infections reflects the case complexity and not necessarily a problem with the flaps. However, this series highlights the need to continue to explore alternative approaches to managing this difficult clinical problem. Future studies should aim to establish an evidence-based reconstructive algorithm, focusing on host, wound, and timing characteristics that may maximize outcomes. Level of Evidence Level IV, therapeutic study.

\section{Introduction}

Wound complications can occur in as many as $20 \%$ of patients after TKA [1]. Galat et al. [7] found that $0.33 \%$ of patients undergoing TKA will have wound complications requiring surgical treatment, but those who did were five times more likely to undergo major operative intervention compared with patients without wound complications. In particular, postoperative wounds that progress to substantial skin necrosis and exposure of the underlying hardware greatly increase the risk of having a deep periprosthetic infection develop, potentially initiating a catastrophic cascade leading to loss of the prosthesis and arthrodesis or amputation of the limb $[5,16]$.

Although several techniques have been developed for providing coverage of the exposed prosthesis, the medial gastrocnemius flap continues to be the preferred method of soft tissue reconstruction [8, 28]. This axial-pattern flap is particularly versatile owing to its substantial size and mobility. It provides a vascular bed for an overlying skin graft and facilitates improved delivery of oxygen, systemic antibiotics, and immune modulators to the infected joint $[8$, 25]. Although some authors have reported favorable outcomes after medial gastrocnemius flap coverage after TKA, with prosthesis retention rates as high as $82 \%$ to $92 \%$ [8, 23, 28], the largest English-language series to our knowledge included only 22 medial gastrocnemius flaps [6]. With an increasing number of patients undergoing TKA [14], the number of cases of periprosthetic joint infection also is increasing. Better understanding of outcomes after medial gastrocnemius flap coverage, including risk factors for treatment failure, will help to guide management of soft tissue defects in this setting.
We therefore reviewed our experience with medial gastrocnemius flaps to answer the following questions: (1) What were the rates of persistent or recurrent infection, implant survivorship, flap-related complications, and reoperation for patients who underwent medial gastrocnemius flap reconstruction after TKA? (2) What were the Knee Society clinical and functional scores for patients who underwent medial gastrocnemius flap reconstruction for soft tissue defects after TKA? (3) What were risk factors for failure of medial gastrocnemius flap reconstruction after TKA, with failure defined as recurrent or new periprosthetic joint infection or inability to reimplant the TKA prosthesis?

\section{Methods}

Between 2003 and 2011, four surgeons (RWW, JJF, GHD, SRS) at one institution performed 31 medial gastrocnemius flaps for soft tissue coverage over an infected TKA. Of those, $27(87 \%)$ patients were available for followup at a minimum of 2 years (mean, 4 years; range, 2-6 years), although patients experiencing complications or treatment failures before 2 years were included. The study group consisted of 15 men and 12 women with a mean age of 61 years at the time of surgery (range, 36-86 years). During the period in question, the general indication for using a gastrocnemius flap in this setting was deficient soft tissue over the anterior knee. More specifically, healing by secondary intention was favored in cases of partial-thickness skin breakdown where reepithelialization would be expected in 10 to 14 days. Negative-pressure vacuum-assisted closure followed by skin grafting was done for fullthickness defects in the absence of infection with deep tissue such as muscle or fascia that can form granulation tissue. Flap coverage was favored when full-thickness defects presented exposed tendon, bone, or implant, or when full thickness surgical incisions were unable to be closed under appropriate tension, often in the setting of infection when a draining sinus had been débrided. The gastrocnemius flap is most useful for open defects at or distal to the inferior pole of the patella. Wounds proximal to that zone are often outside the reach of the gastrocnemius and can require thigh-based coverage (gracilis or sartorius muscle flaps, perforator soft tissue flaps) or free flaps. Two procedures followed a primary TKA and 25 followed a revision TKA (average number of prior knee surgeries, four; range, 1-11). The four excluded patients included two lost to followup after prosthesis reimplantation (at 3 and 9 months with no known complications) and two who were deceased before 2 years (one before attempted prosthesis reimplantation and one 3 months after revision TKA). 


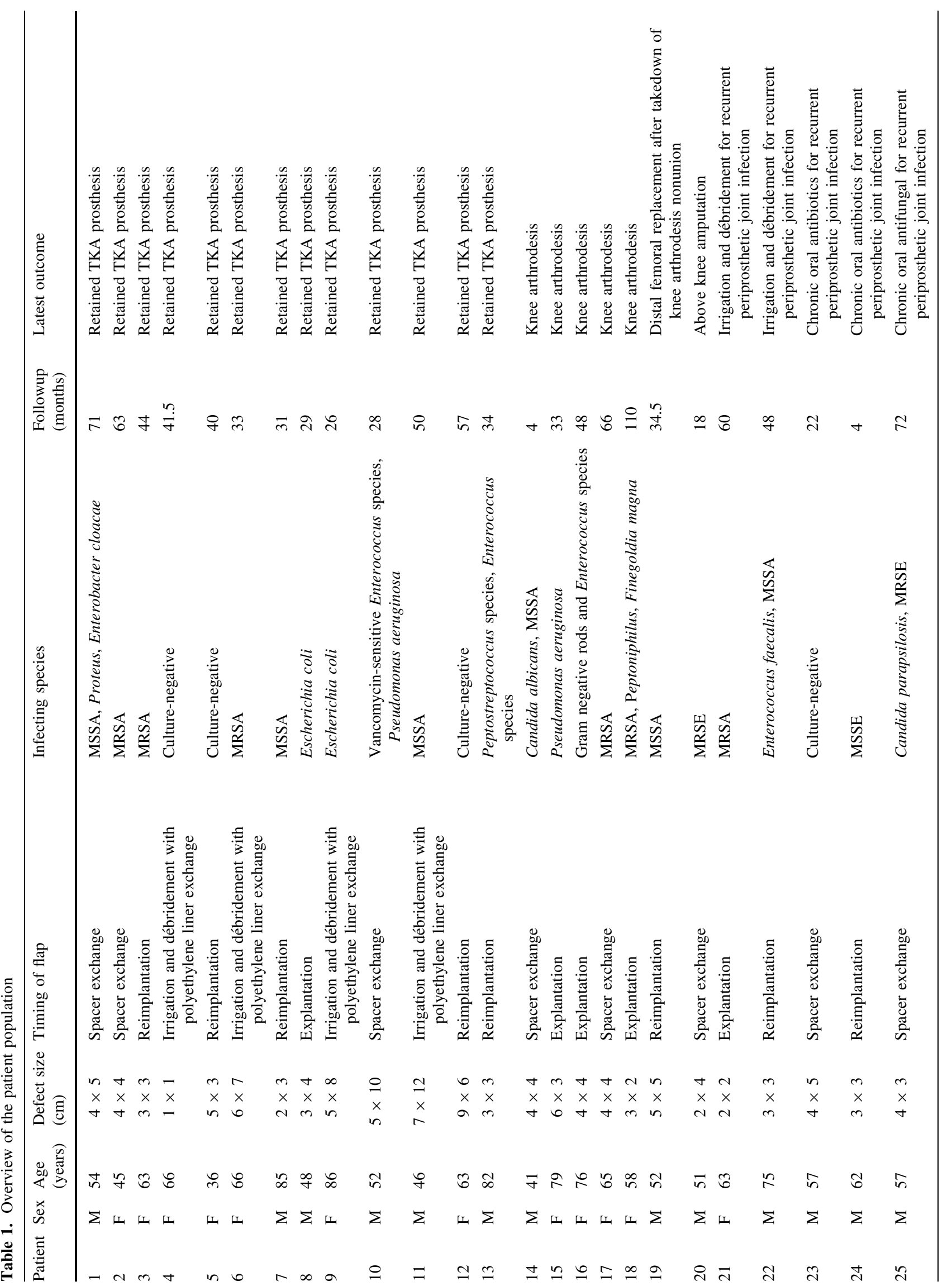


All patients met Musculoskeletal Infection Society criteria for periprosthetic joint infection [26], with the most common infecting organisms being Staphylococcal species (Table 1); eight patients had a polymicrobial infection and four were culture negative.

Six of the flaps were performed at the time of prosthetic explantation and antibiotic spacer placement, eight at the time of a spacer exchange, eight at the time of second-stage reimplantation, and five at the time of débridement with a modular polyethylene liner exchange. The decision to place the flap at a certain stage versus another was based solely on when the soft tissues were deemed insufficient, without any bias or belief that one stage was superior to another. For example, patients with large open wounds or draining sinuses at the time of explantation for infection often had soft tissues that were unable to be closed at that time, and thus flaps were performed concurrently. Deep infections without drainage or open wounds often were able to be closed at explantation but could require a flap at reimplantation if there was added bulk from new arthroplasty implants, or anterior soft tissues that were under too much tension to resist failing in knee flexion. The flap coverage procedures were performed by an attending plastic surgeon (GHD, SRS) (eight cases) or by a microsurgical fellowship-trained attending orthopaedic hand surgeon (RWW, JJF) (19 cases). The medial vascular pedicle was identified and the medial gastrocnemius head was released and brought anteriorly through a subcutaneous tunnel. The flap was sutured to surrounding soft tissues and primary closure was performed with use of a split-thickness skin graft harvested from the lateral thigh. Care was taken to minimize tension on the wound edges. The mean defect size was $20 \mathrm{~cm}^{2}$ (range, $1-84 \mathrm{~cm}^{2}$ ). One patient underwent concomitant patellar tendon reconstruction with Achilles tendon autograft.

Intravenous antibiotics were administered for a minimum of 6 weeks in all patients but those undergoing second-stage reimplantations. For patients who had resection arthroplasties, the antibiotic therapy was followed by a minimum 2-week antibiotic-free interval before attempted reimplantation. The knee was immobilized for 2 to 3 weeks to protect the flap if an articulating spacer was used or if the prosthesis was retained. Care of the flap included a bolster dressing, with the knee in extension for 1 week, followed by routine wet to dry dressing changes over the skin graft and transition to a moisturizer as the graft matured, typically during 4 weeks. ROM typically was started at 2 to 3 weeks once the flap and skin graft showed good survival, assuming a static spacer was not in place. Reimplantation ultimately was attempted in 18 of 22 (82\%) patients who underwent concurrent resection arthroplasty.

Postoperatively, all patients were assessed clinically at regular intervals. Data are presented as of the most recent 
Table 2. Clinical outcome scores for medial gastrocnemius flaps after TKA

\begin{tabular}{|c|c|c|c|c|}
\hline Group & Score & Preoperative & Most recent & $\mathrm{p}$ Value \\
\hline \multirow[t]{2}{*}{ Entire cohort $(n=27)$} & KSS knee & $38(18)$ & $65(20)$ & $<0.001$ \\
\hline & KSS function & $20(22)$ & $37(25)$ & 0.002 \\
\hline \multirow[t]{2}{*}{ Successful treatment $(n=13)$} & KSS knee & $38(19)$ & $74(22)$ & $<0.001$ \\
\hline & KSS function & $24(25)$ & $53(21)$ & 0.001 \\
\hline \multirow[t]{2}{*}{ Treatment failure $(\mathrm{n}=14)$} & KSS knee & $38(17)$ & $56(15)$ & 0.010 \\
\hline & KSS function & $16(20)$ & $23(20)$ & 0.309 \\
\hline
\end{tabular}

Values = mean, with SD in parentheses; KSS = Knee Society Score.

followup or at the time of failure as defined earlier. Outcomes scores were drawn from a longitudinal institutional registry. The registry is populated by clinical outcomes as measured by independent observers (clinical nurses, residents, and fellows).

Potential risk factors for complications, including age, sex, BMI, Charlson comorbidity index [4], diabetes, smoking status, coronary artery disease, prior number of knee arthrotomies, prior extensor mechanism disruption, prior completed two-stage revision, skin defect size, surgical service performing flap (plastic surgery vs orthopaedics), knee procedure at the time of flap reconstruction, type of spacer used (articulating vs static) in patients who underwent resection TKA, and identity and antibiotic-resistance of infecting organism(s), were recorded. Patients were classified as having treatment failure if they experienced persistent or recurrent periprosthetic joint infection [26] and/or ultimately underwent reoperation, including removal of the prosthetic components, arthrodesis, or amputation. Individuals who retained their prosthesis without evidence of recurrent infection were classified as having a successful result.

\section{Statistical Analysis}

Descriptive analysis consisted of frequencies and percentages for discrete data and means and SD for continuous data. Paired Student's T-tests were used to compare preoperative and postoperative clinical scores whereas unpaired T-tests were used to compare scores between groups. Patient and procedural characteristics were tested for association with failure using Cox proportional hazards modeling. Multivariate analysis was precluded by insufficient sample size. The level of significance was set at $p$ less than 0.05. However, because there were 19 individual patient and procedural characteristics tested for association with failure, for these tests, the Bonferroni correction required lowering the level of significance to $\mathrm{p}$ less than 0.004 .

\section{Results}

Fourteen of 27 (52\%) patients had persistent or recurrent infections; this occurred at a mean of 13 months (range, 0.5-72 months). Survivorship of the index TKA prosthesis at 4 years was $48 \%(95 \% \mathrm{CI}, 31 \%-66 \%)$. There were no flap or donor site complications. Twelve patients had a total of 19 reoperations during the study period after the index treatment for infection. All reoperations occurred in the group with persistent or recurrent infections; these included: six knee arthrodeses with one distal femoral replacement after a failed arthrodesis, one above knee amputation, one tibial component revision for periprosthetic fracture, five irrigation and débridement procedures with polyethylene exchange, and four TKA prosthesis explantations with antibiotic spacer placement, one with subsequent replantation of a prosthesis. Two patients received chronic oral antibiotic suppression for repeat periprosthetic joint infections with retained implants; these patients were considered as having treatment failure. Two patients also underwent manipulation under anesthesia for knee stiffness.

For the cohort as a whole, mean Knee Society (KSS) knee and function scores [12] improved (Table 2). The preoperative KSS knee score (mean \pm SD) increased from $38 \pm 18$ to $65 \pm 20(\mathrm{p}<0.001)$ and KSS function from 20 \pm 22 to $37 \pm 25(\mathrm{p}=0.002)$ at most recent followup. The final KSS knee score was graded as excellent (score of 80 to 100$)$ in eight patients $(31 \%)$, good (70 to 79$)$ in four (15\%), fair (60 to 69) in three $(12 \%)$, and poor $(<60)$ in 11 (42\%) [2] (excluding the patient with an above knee amputation, as the score is based on objective parameters about the knee). Patients who underwent successful flap treatment experienced far greater increases in both components of the KSS score (Table 2). Although patients with failed treatment also experienced increases in mean scores, the KSS knee mean score was less than 60 points and the function scores were extremely poor.

With the numbers available, treatment failure was not associated with age, sex, BMI, Charlson comorbidity index, 
Table 3. Associations of patient and procedural characteristics with success versus failure of medial gastrocnemius flap (bivariate analysis)

\begin{tabular}{|c|c|c|c|c|}
\hline Characteristic & $\begin{array}{l}\text { Mean for successful } \\
\text { treatment* }\end{array}$ & $\begin{array}{l}\text { Mean for failed } \\
\text { treatment* }\end{array}$ & $\begin{array}{l}\text { Number of } \\
\text { failures (percent) }\end{array}$ & $\overline{p \text { Value }^{\dagger}}$ \\
\hline Age (years) & $61 \pm 16$ & $62 \pm 11$ & $\mathrm{n} / \mathrm{a}$ & 0.950 \\
\hline Sex & & & & 0.476 \\
\hline Female $(\mathrm{n}=12)$ & $\mathrm{n} / \mathrm{a}$ & $\mathrm{n} / \mathrm{a}$ & $5(42 \%)$ & \\
\hline Male $(\mathrm{n}=15)$ & $\mathrm{n} / \mathrm{a}$ & $\mathrm{n} / \mathrm{a}$ & $9(60 \%)$ & \\
\hline BMI $\left(\mathrm{kg} / \mathrm{m}^{2}\right)$ & $35 \pm 8$ & $33 \pm 7$ & $\mathrm{n} / \mathrm{a}$ & 0.326 \\
\hline Charlson comorbidity index & $1.4 \pm 1.5$ & $1.4 \pm 1.3$ & $\mathrm{n} / \mathrm{a}$ & 0.826 \\
\hline Diabetes mellitus & & & & 0.786 \\
\hline No $(n=22)$ & $\mathrm{n} / \mathrm{a}$ & $\mathrm{n} / \mathrm{a}$ & $12(55 \%)$ & \\
\hline Yes $(n=5)$ & $\mathrm{n} / \mathrm{a}$ & $\mathrm{n} / \mathrm{a}$ & $2(40 \%)$ & \\
\hline Smoker & & & & 0.853 \\
\hline No $(\mathrm{n}=25)$ & $\mathrm{n} / \mathrm{a}$ & $\mathrm{n} / \mathrm{a}$ & $13(52 \%)$ & \\
\hline Yes $(n=2)$ & $\mathrm{n} / \mathrm{a}$ & $\mathrm{n} / \mathrm{a}$ & $1(50 \%)$ & \\
\hline Coronary artery disease & & & & 0.382 \\
\hline No $(n=21)$ & $\mathrm{n} / \mathrm{a}$ & $\mathrm{n} / \mathrm{a}$ & $12(57 \%)$ & \\
\hline Yes $(n=6)$ & $\mathrm{n} / \mathrm{a}$ & $\mathrm{n} / \mathrm{a}$ & $2(33 \%)$ & \\
\hline Number of knee arthrotomies before flap & $3.7 \pm 2.4$ & $4.3 \pm 2.8$ & $\mathrm{n} / \mathrm{a}$ & 0.354 \\
\hline Prior extensor mechanism disruption & & & & 0.361 \\
\hline No $(\mathrm{n}=21)$ & $\mathrm{n} / \mathrm{a}$ & $\mathrm{n} / \mathrm{a}$ & $9(43 \%)$ & \\
\hline Yes $(n=6)$ & $\mathrm{n} / \mathrm{a}$ & $\mathrm{n} / \mathrm{a}$ & $5(83 \%)$ & \\
\hline Prior completed two-stage revision & & & & 0.313 \\
\hline No $(n=22)$ & $\mathrm{n} / \mathrm{a}$ & $\mathrm{n} / \mathrm{a}$ & $11(50 \%)$ & \\
\hline Yes $(n=5)$ & $\mathrm{n} / \mathrm{a}$ & $\mathrm{n} / \mathrm{a}$ & $3(60 \%)$ & \\
\hline Defect area $\left(\mathrm{cm}^{2}\right)$ & $28 \pm 25$ & $14 \pm 6$ & $\mathrm{n} / \mathrm{a}$ & 0.197 \\
\hline Surgical service performing flap & & & & 0.575 \\
\hline Plastic surgery $(n=8)$ & $\mathrm{n} / \mathrm{a}$ & $\mathrm{n} / \mathrm{a}$ & $5(63 \%)$ & \\
\hline Orthopaedics $(\mathrm{n}=19)$ & $\mathrm{n} / \mathrm{a}$ & $\mathrm{n} / \mathrm{a}$ & $9(47 \%)$ & \\
\hline Knee procedure at time of flap & & & & 0.033 \\
\hline $\begin{array}{l}\text { Irrigation and débridement or TKA prosthesis } \\
\text { replantation }(\mathrm{n}=13)\end{array}$ & $\mathrm{n} / \mathrm{a}$ & $\mathrm{n} / \mathrm{a}$ & $4(31 \%)$ & \\
\hline Spacer placement/exchange $(\mathrm{n}=14)$ & $\mathrm{n} / \mathrm{a}$ & $\mathrm{n} / \mathrm{a}$ & $10(71 \%)$ & \\
\hline Type of spacer if flap part of two-stage & & & & 0.261 \\
\hline None/TKA irrigation and débridement $(\mathrm{n}=5)$ & $\mathrm{n} / \mathrm{a}$ & $\mathrm{n} / \mathrm{a}$ & $1(20 \%)$ & \\
\hline Static $(\mathrm{n}=12)$ & $\mathrm{n} / \mathrm{a}$ & $\mathrm{n} / \mathrm{a}$ & $8(67 \%)$ & \\
\hline Articulating $(\mathrm{n}=10)$ & $\mathrm{n} / \mathrm{a}$ & $\mathrm{n} / \mathrm{a}$ & $5(50 \%)$ & \\
\hline Growth of Staphyloccus aureus & & & & 0.721 \\
\hline No $(n=14)$ & $\mathrm{n} / \mathrm{a}$ & $\mathrm{n} / \mathrm{a}$ & $7(50 \%)$ & \\
\hline Yes $(\mathrm{n}=13)$ & $\mathrm{n} / \mathrm{a}$ & $\mathrm{n} / \mathrm{a}$ & $7(54 \%)$ & \\
\hline Growth of Enterococcus & & & & 0.749 \\
\hline No $(n=23)$ & $\mathrm{n} / \mathrm{a}$ & $\mathrm{n} / \mathrm{a}$ & $12(52 \%)$ & \\
\hline Yes $(n=4)$ & $\mathrm{n} / \mathrm{a}$ & $\mathrm{n} / \mathrm{a}$ & $2(50 \%)$ & \\
\hline Growth of Gram-negative rods & & & & 0.911 \\
\hline No $(n=20)$ & $\mathrm{n} / \mathrm{a}$ & $\mathrm{n} / \mathrm{a}$ & $11(55 \%)$ & \\
\hline Yes $(n=7)$ & $\mathrm{n} / \mathrm{a}$ & $\mathrm{n} / \mathrm{a}$ & $3(43 \%)$ & \\
\hline Growth of resistant bacteria (MRSA/VRE) & & & & 0.235 \\
\hline No $(\mathrm{n}=19)$ & $\mathrm{n} / \mathrm{a}$ & $\mathrm{n} / \mathrm{a}$ & $9(47 \%)$ & \\
\hline Yes $(n=8)$ & $\mathrm{n} / \mathrm{a}$ & $\mathrm{n} / \mathrm{a}$ & $5(63 \%)$ & \\
\hline
\end{tabular}


Table 3. continued

\begin{tabular}{llll}
\hline Characteristic & $\begin{array}{l}\text { Mean for successful } \\
\text { treatment* }\end{array}$ & $\begin{array}{l}\text { Mean for failed } \\
\text { treatment* }\end{array}$ & $\begin{array}{l}\text { Number of } \\
\text { failures (percent) }\end{array}$ \\
\hline $\begin{array}{l}\text { Polymicrobial growth } \\
\text { No }(\mathrm{n}=19)\end{array}$ & $\mathrm{n} / \mathrm{a}$ & $\mathrm{n} / \mathrm{a}$ & 9.270 \\
Yes $(\mathrm{n}=8)$ & $\mathrm{n} / \mathrm{a}$ & $\mathrm{n} / \mathrm{a}$ & $5(47 \%)$ \\
\hline
\end{tabular}

* Mean $\pm \mathrm{SD} ;{ }^{\dagger} \mathrm{p}$ values are from Cox proportional hazards survival analysis models. A Bonferroni correction was applied owing to the large number of univariate statistical tests; 19 tests were performed, requiring that the level of significance be lowered from 0.05 to 0.004 , therefore no $\mathrm{p}$ value in this table was considered to be statistically significant; $\mathrm{n} / \mathrm{a}=$ not applicable; MRSA = methicillin-resistant Staphylococcus aureus; VRE = vancomycin-resistant Enterococcus .

diabetes mellitus, smoking status, coronary artery disease, number of knee arthrotomies before flap coverage, extensor mechanism rupture, prior completed two-stage revision, area of skin defect, surgical service that performed flap, knee procedure being performed at the time of the flap, spacer type (if flap was part of a two-stage exchange), or growth of Staphylococcus aureus, Enterococcus, Gram-negative rods, or antibiotic-resistant bacteria ( $\mathrm{p}>0.004$ for each; Table 3). There was a trend toward failure when flap coverage was performed at the same time as antibiotic spacer placement or exchange compared with at the time of irrigation and débridement or replantation of a prosthesis, but this did not reach statistical significance $(71 \%$ vs $31 \%$; $p=0.033)$. In particular, the treatment failure rate was one of five $(20 \%)$ with irrigation and débridement, three of eight $(38 \%)$ with reimplantation, five of eight $(63 \%)$ with spacer exchange, and five of six $(83 \%)$ with explantation.

\section{Discussion}

Wound complications after TKA may have devastating consequences. Previous studies have reported high rates of prosthetic retention and fairly low rates of periprosthetic infection after the use of medial gastrocnemius flaps for soft tissue coverage [8, 23, 24, 28]. However, most of these studies were small and did not evaluate risk factors for failure. In what we believe is the largest series of patients who underwent medial gastrocnemius flaps in the setting of periprosthetic joint infection after TKA, we thus evaluated (1) the rate of persistent or recurrent infection, implant survivorship, flap-related complications and reoperation, (2) clinical outcomes, and (3) risk factors for persistent or recurrent infection when a flap was used.

This study has several limitations that should be considered when interpreting our results. First, our investigation was retrospective and therefore was subject to selection bias and a lack of uniformity, including the varied timing of procedures. During the study period, we generally adhered to consistent indications and a treatment algorithm for soft tissue coverage that was described above and hopefully limited selection bias. However, it is possible that our study cohort, which consisted mostly of patients with multiple operations and chronic infections who were referred to our tertiary referral center, may have benefitted from flap coverage earlier during the course of infection (eg, for modest wound drainage rather than exposed implant). Although variability is inherent in complex cases in the revision setting, the performance of all flap procedures by a small group of four microsurgery-trained attending surgeons (RWW, JJF, GHD, SRS) helped to minimize heterogeneity in surgical technique. Second, the number of patients included in our series likely provided inadequate power to detect factors that portended poorer prognosis after flap coverage. Sample size also precluded multivariate analysis to control for confounding variables. However, to our knowledge, this is the largest reported series of medial gastrocnemius flaps after TKA. Although our risk factor analysis did not identify statistically significant predictors of treatment failure, it provides a basis for further investigation of factors that may negatively affect treatment outcomes, such as timing of flap coverage. Third, the average followup in our cohort was relatively short, although the viability of a flap generally can be determined early, and failures of recurrent or persistent infection often are known early as well. The high observed failure rate suggests that a gastrocnemius flap for treatment of a periprosthetic infection should be viewed as a salvage procedure. Although longer-term data and prospective clinical studies are warranted, the results of this retrospective series may help surgeons identify and counsel patients who may be at risk of failed treatment after medial gastrocnemius flap reconstruction after TKA.

The observed high frequency of recurrent or persistent periprosthetic joint infection and low frequency of prosthetic retention compare poorly with results of two prior studies that examined the outcomes of gastrocnemius muscle flap reconstruction for infected TKAs [6, 19] (Table 4). The poorer results in our cohort may be partly attributable to a greater number of knee operations before flap coverage and/or greater soft tissue loss. Corten et al. 


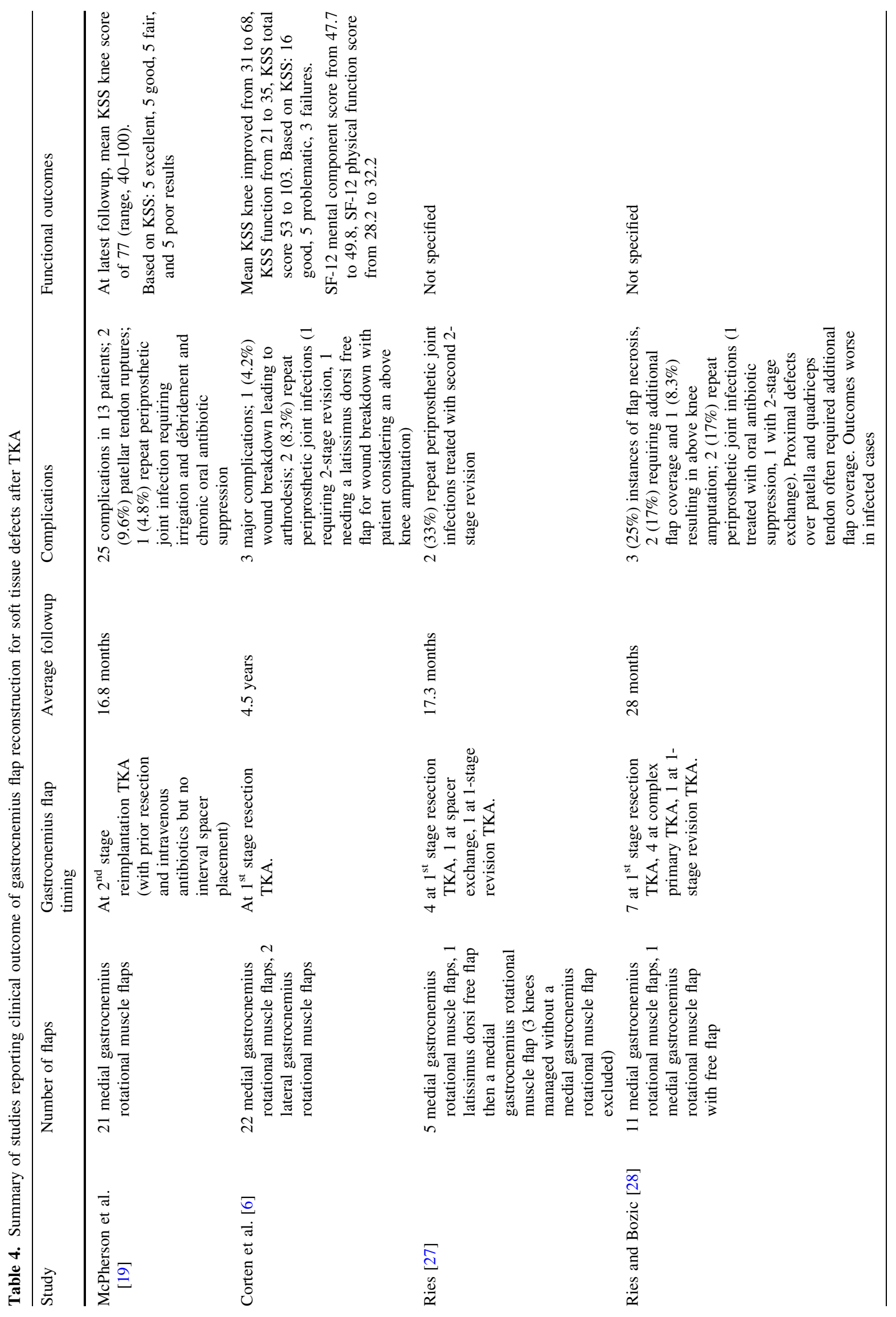




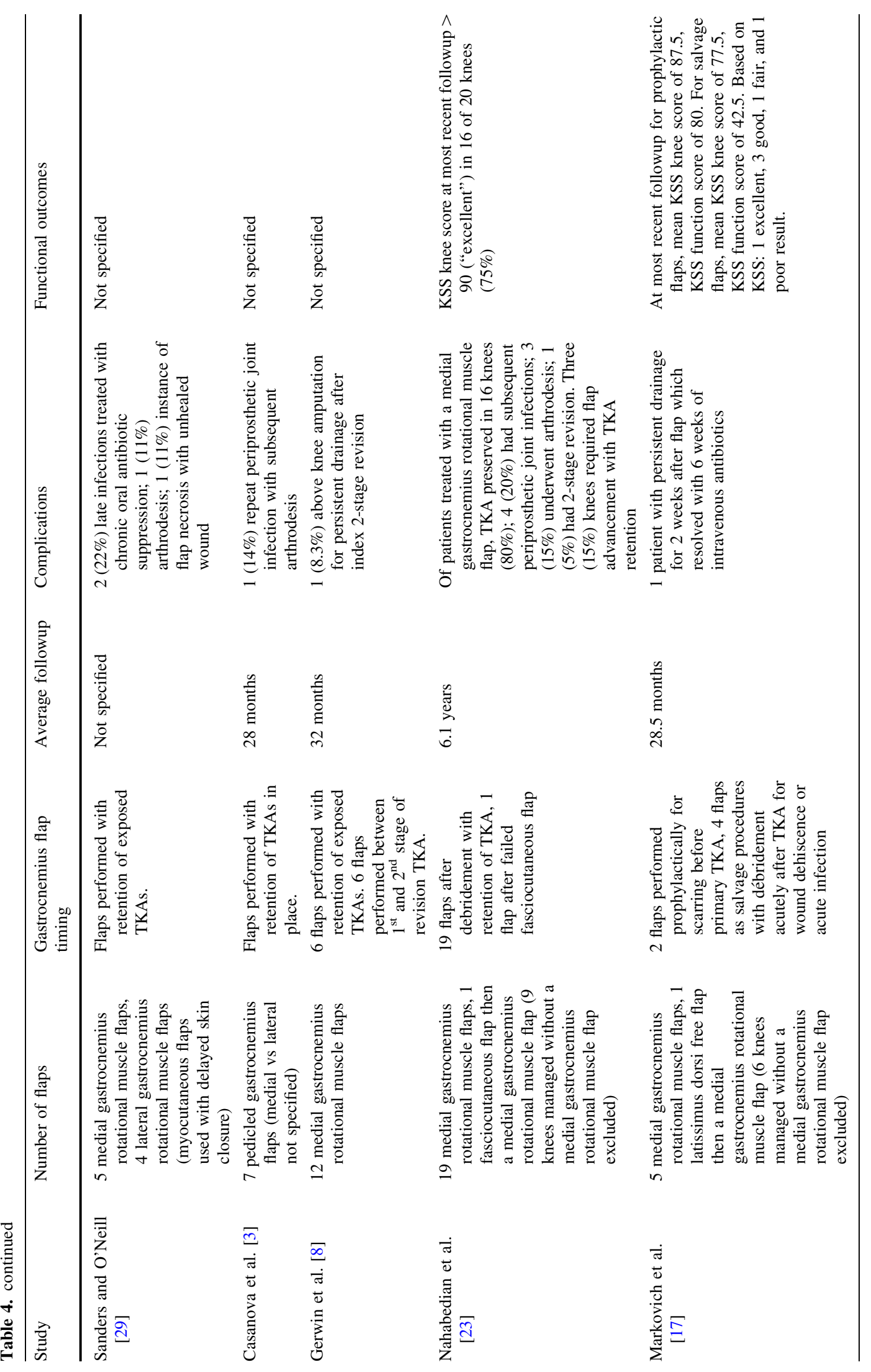




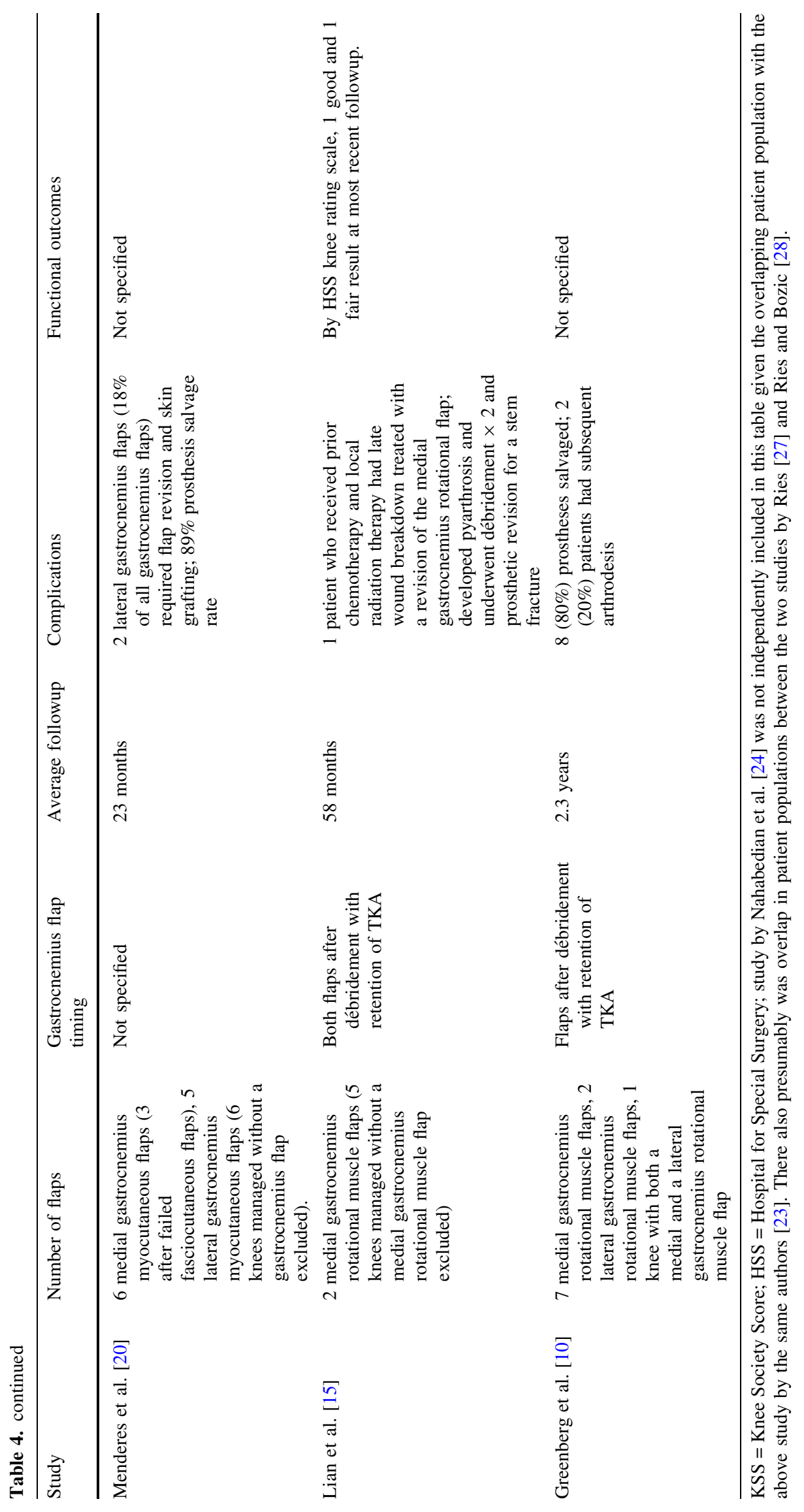


[6] reported that $42 \%$ of their flaps followed a primary TKA versus only $7 \%$ in our cohort, while McPherson et al. [19] reported a mean of 3.4 (range, 1-6 operations) prior knee procedures compared with four (range, 1-11 operations) in our cohort, seemingly a lesser difference. Meanwhile, neither study reported a measure of soft tissue loss at the time of flap coverage; it is plausible that the substantial soft tissue loss (average defect area of $20 \mathrm{~cm}^{2}$ ) in our study group contributed to comparatively poorer outcomes. Success of two-stage exchange arthroplasty for periprosthetic infection has been reported to be between $66 \%$ and $91 \%$ in several large series [9, 21, 22, 30]. Our study supports some previous studies [7, 22, 23] that showed that patients should be counseled that the results of two-stage exchange arthroplasty for infection are worse in the presence of superimposed soft tissue compromise warranting flap reconstruction. It would be beneficial for future studies to prospectively compare alternative modalities for soft tissue coverage for similar defects in similar hosts. We suspect that our observed rates of repeat infection and prosthetic retention are a product of substantial soft tissue loss in patients who had multiple operations and less a function of the medial gastrocnemius flap, although our study design does not allow for such insight.

Outcome scores in our series were low (Table 2) compared with those of previous studies evaluating functional parameters after TKA flap coverage (Table 4). The fact that all flaps reliably healed suggests that subsequent poor function may be tied to the severity of soft tissue compromise and underlying prosthetic infection rather than flap choice or technique. It is possible that earlier ROM of the knee after flap coverage may have improved functional outcomes, however, investigators who reported ranging the knee as early as 10 days also reported a higher rate of wound complications [19]. Although sensation in the flap is poor, the functional loss and comorbidity associated with the flap is generally minimal because of compensation provided by the remaining soleus and hemigastrocnemius muscle [11, 18]. For these reasons and ease of surgical accessibility and reach of the flap, we continue to prefer the medial gastrocnemius for soft tissue cover at revision TKA for full thickness defects at or distal to the inferior pole of the patella, or for surgical incisions that cannot be closed under appropriate tension. We generally reserve thigh-based coverage (gracilis or sartorius muscle flaps, perforator soft tissue flaps) or free flaps for wounds proximal to that zone or cases when a gastrocnemius flap fails. Future work could explore the functional implications of duration of immobilization after flap coverage over the anterior knee and whether there is any role for expanding the indications for thigh-based coverage or free flaps. There also may be value in investigating whether there is a functional argument for earlier consideration of arthrodesis in the challenging treatment of patients with recalcitrant periprosthetic joint infection and wound breakdown $[5,11]$.

We were unable to identify factors associated with failure of gastrocnemius flap reconstruction for an infected TKA with the numbers available. Although some authors $[8,19,20,31]$ have proposed poor prognostic factors based on smaller series, our study is the first, to our knowledge, to statistically evaluate factors associated with flap failure in this setting. There was a trend toward failure when flap coverage was performed at the same time as antibiotic spacer placement but this did not reach statistical significance. Although acceptable results have been reported with performance of the gastrocnemius flap at first-stage resection TKA [6] and at second-stage reimplantation [19], our findings suggest that in the setting of two-stage exchange arthroplasty, delaying flap coverage until after treatment of infection may be advisable if the soft tissue is amenable to closure at the time of resection or spacer exchange. Alternatively, it is plausible that patients who underwent flap coverage with spacer placement had more severe soft tissue defects, which contributed to poorer outcomes. Patients in our study generally had multiple prior knee procedures (four on average), which may have contributed to poor outcomes overall secondary to decreased blood supply and residual scarring [13], but we were unable to isolate this variable as an independent risk factor for treatment failure. We similarly were unable to substantiate other potential risk factors for failure of salvage muscle flaps, including sex, age, BMI, infecting organism, type of antibiotic spacer, or individual comorbidities (tobacco use [20, 31], reflex sympathetic dystrophy syndrome [19], diabetes [19, 20], chronic renal failure [20], peripheral vascular disease [20], and steroid use [20]). Despite these no-difference findings, the study may have been underpowered and the optimization of modifiable variables is advised perioperatively, when possible. Although some studies cite superficial culture results as risk factors for poor prognosis $[8,31]$, we recommend against routine microbiologic swabbing of draining wounds owing to the high risk of bacterial contamination [25, 32].

In this large retrospective series, medial gastrocnemius flaps were used to address difficult soft tissue defects during the treatment of deep infections. The high proportion of patients experiencing persistent or recurrent infections reflects the case complexity and not necessarily a problem with the flaps; these are challenging cases with few alternatives. Unfortunately we were unable to establish significance in evaluating a multitude of factors for association with treatment failure. However, this study highlights the need to continue to explore alternative approaches to managing this vexing clinical problem. Future work should aim to establish an evidence-based reconstructive algorithm, focusing on host, wound, and 
timing characteristics that may maximize outcomes or facilitate alternative flaps.

Acknowledgements We acknowledge John J. Fernandez MD (Department of Orthopaedic Surgery, Rush University Medical Center), Gordon H. Derman MD (Department of Plastic and Reconstructive Surgery, Rush University Medical Center), and Steven R. Sigalove MD (Department of Plastic Surgery, DuPage Medical Group), who performed the gastrocnemius flaps included in this study.

\section{References}

1. Alexiades M, Sands A, Craig S, Scott WN. Management of selected problems in revision knee arthroplasty. Orthop Clin North Am. 1989;20:211-219.

2. Asif S, Choon DS. Midterm results of cemented Press Fit Condylar Sigma total knee arthroplasty system. J Orthop Surg (Hong Kong). 2005;13:280-284.

3. Casanova D, Hulard O, Zalta R, Bardot J, Magalon G. Management of wounds of exposed or infected knee prostheses. Scand J Plast Reconstr Hand Surg. 2001;35:71-77.

4. Charlson M, Szatrowski TP, Peterson J, Gold J. Validation of a combined comorbidity index. J Clin Epidemiol. 1994;47:1245-1251.

5. Conway JD, Mont MA, Bezwada HP. Arthrodesis of the knee. J Bone Joint Surg Am. 2004;86:835-848.

6. Corten K, Struelens B, Evans B, Graham E, Bourne RB, MacDonald SJ. Gastrocnemius flap reconstruction of soft-tissue defects following infected total knee replacement. Bone Joint J. 2013;95:1217-1221.

7. Galat DD, McGovern SC, Larson DR, Harrington JR, Hanssen AD, Clarke HD. Surgical treatment of early wound complications following primary total knee arthroplasty. J Bone Joint Surg Am. 2009;91:48-54.

8. Gerwin M, Rothaus KO, Windsor RE, Brause BD, Insall JN. Gastrocnemius muscle flap coverage of exposed or infected knee prosthesis. Clin Orthop Relat Res. 1993;286:64-70.

9. Goldman RT, Scuderi GR, Insall JN. 2-stage reimplantation for infected total knee replacement. Clin Orthop Relat Res. 1996;331:118-124.

10. Greenberg B, LaRossa D, Lotke PA, Murphy JB, Noone RB. Salvage of jeopardized total-knee prosthesis: the role of the gastrocnemius muscle flap. Plast Reconstr Surg. 1989;83:85-89, 97-99.

11. Harris IE, Leff AR, Gitelis S, Simon MA. Function after amputation, arthrodesis, or arthroplasty for tumors about the knee. J Bone Joint Surg Am. 1990;72:1477-1485.

12. Insall JN, Dorr LD, Scott RD, Scott WN. Rationale of the Knee Society clinical rating system. Clin Orthop Relat Res. 1989;248:13-14.

13. Jones RE, Russell RD, Huo MH. Wound healing in total joint replacement. Bone Joint J. 2013;95(11 suppl A):144-147.

14. Kurtz S, Ong K, Lau E, Mowat F, Halpern M. Projections of primary and revision hip and knee arthroplasty in the United States from 2005 to 2030. J Bone Joint Surg Am. 2007;89:780-785.

15. Lian G, Cracchiolo A 3rd, Lesavoy M. Treatment of major wound necrosis following total knee arthroplasty. J Arthroplasty. 1989;4(suppl):S23-32.
16. Lidwell OM, Lowbury EJ, Whyte W, Blowers R, Stanley SJ, Lowe D. Infection and sepsis after operations for total hip or knee-joint replacement: influence of ultraclean air, prophylactic antibiotics and other factors. J Hyg (Lond). 1984;93:505-529.

17. Markovich GD, Dorr LD, Klein NE, McPherson EJ, Vince KG. Muscle flaps in total knee arthroplasty. Clin Orthop Relat Res. 1995;321:122-130.

18. McCraw JB, Fishman JH, Sharzer LA. The versatile gastrocnemius myocutaneous flap. Plast Reconstr Surg. 1978;62:15-23.

19. McPherson EJ, Patzakis MJ, Gross JE, Holtom PD, Song M, Dorr LD. Infected total knee arthroplasty: two stage reimplantation with a gastrocnemius rotational flap. Clin Orthop Relat Res. 1997;341:73-81.

20. Menderes A, Demirdover C, Yilmaz M, Vayvada H, Barutcu A. Reconstruction of soft tissue defects following total knee arthroplasty. Knee. 2002;9:215-219.

21. Mittal Y, Fehring TK, Hanssen A, Marculescu C, Odum SM, Osmon D. Two-stage reimplantation for periprosthetic knee infection involving resistant organisms. J Bone Joint Surg Am. 2007;89:1227-1231.

22. Mortazavi SM, Vegari D, Ho A, Zmistowki B, Parvizi J. Twoexchange arthroplasty for infected total knee arthroplasty: predictors of failure. Clin Orthop Relat Res. 2011;469:3049-3054.

23. Nahabedian MY, Mont MA, Orlando JC, Delanois RE, Hungerford DS. Operative management and outcome of complex wounds following total knee arthroplasty. Plast Reconstr Surg. 1999;104:1688-1697.

24. Nahabedian MY, Orlando JC, Delanois RE, Mont MA, Hungerford DS. Salvage procedures for complex soft tissue defects of the knee. Clin Orthop Relat Res. 1998;356:119-124.

25. Panni AS, Vasso M, Cerciello S, Salgarello M. Wound complications in total knee arthroplasty: which flap is to be used? With or without retention of prosthesis? Knee Surg Sports Traumatol Arthrosc. 2011;19:1060-1068.

26. Parvizi J, Zmistowski B, Berbari EF, Bauer TW, Springer BD, Della Valle CJ, Garvin KL, Mont MA, Wongworawat MD, Zalavras CG. New definition for periprosthetic joint infection: from the Workgroup of the Musculoskeletal Infection Society. Clin Orthop Relat Res. 2011;469:2992-2994.

27. Ries MD. Skin necrosis after total knee arthroplasty. J Arthroplasty. 2002;17(4 suppl 1):74-77.

28. Ries MD, Bozic KJ. Medial gastrocnemius flap coverage for treatment of skin necrosis after total knee arthroplasty. Clin Orthop Relat Res. 2006;446:186-192.

29. Sanders R, O'Neill T. The gastrocnemius myocutaneous flap used as a cover for the exposed knee prosthesis. J Bone Joint Surg Br. 1981;63:383-386.

30. Sherrell JC, Fehring TK, Odum S, Hansen E, Zmistowski B, Dennos A, Kalore N; Periprosthetic Infection Consortium. The Chitranjan Ranawat Award: fate of two-stage reimplantation after failed irrigation and débridement for periprosthetic knee infection. Clin Orthop Relat Res. 2011;469:18-25.

31. Tan KJ, Lim CT, Lim AY. The use of muscle flaps in the salvage of infected exposed implants for internal fixation. $J$ Bone Joint Surg Br. 2010;92:401-405.

32. Tetreault MW, Wetters NG, Aggarwal VK, Moric M, Segreti J, Huddleston JI 3rd, Parvizi J, Della Valle CJ. Should draining wounds and sinuses associated with hip and knee arthroplasties be cultured? J Arthroplasty. 2013;28(8 suppl):133-136. 